\title{
Vertebral artery compression of medulla oblongata causing isolated symptom of dizziness: two case reports
}

\author{
Mahmoud M. Mahrous ${ }^{1,2^{*}}$ (D) and Ibrahim A. Busaad ${ }^{2}$
}

\begin{abstract}
Background: Symptomatic medulla oblongata compressing lesions due to dilated vertebral artery are rare in the literature. The symptoms are extremely heterogeneous and not correlated to the severity of compression in many cases.

Case presentation: This paper describes two cases with vertebral artery compression of medulla oblongata complaining only from dizziness without any other neurological symptoms or signs. In both cases, videonystagmography revealed positional nystagmus. Head magnetic resonance imaging showed abnormal dilatation, elongation, and tortuosity of the vertebral artery compressing the medulla oblongata. Vestibular rehabilitation was described in both cases and had a significant effect on symptom improvement.

Conclusion: In the study cases, the sense of vertigo and/or unsteadiness is due to vertebral artery compression of medulla oblongata and can be an isolated symptom. Positional nystagmus is the only sign in vestibular evaluation.
\end{abstract}

Keywords: Dizziness, Medulla oblongata, Vertebral artery, Dolichoectasia, Vestibular rehabilitation

\section{Background}

Medulla oblongata (MO) compressing lesions are rare in the literature. Most of the reported cases are due to tumor compressions, while it is less common to find vascular indentation [1]. Different vascular pathologies were reported such as fusiform aneurysm, a persisting trigeminal artery, a dolichoectasia of the vertebrobasilar arterial system, and few reported cases of tortuous vertebral artery (VA) compressing the brainstem.

Patients' presentations are extremely heterogeneous; it varies between hemiparesis, leg weakness and tingling, hypertension, dysarthria, headache, visual changes, poor cognition, vertigo and nausea. Vertebral artery compressing the medulla can cause atypical deceiving symptoms.

\footnotetext{
* Correspondence: Mahmoud.mahrous32@gmail.com

${ }^{1}$ Unit of Audio-vestibular medicine, Otorhinolaryngology Department, Faculty of Medicine, Ain Shams University, Cairo, Egypt

${ }^{2}$ Unit of Audio-vestibular medicine, Otorhinolaryngology Department, Faculty of Medicine, Imam Abdulrahman Bin Faisal University, Dammam, Saudi
} Arabia

Gorton et al. [2] reported a case presented with intractmimicking myasthenia gravis.

The largest case series of MO compression was a case of 9 patients published by Savitz et al. [4]. The auMost of the cases of VA compression were reported of the left VA. There is no correlation between neither the $\mathrm{MO}$ compressing lesions difficult to be diagnosed.

Thanement of VA compression of MO is possible literature which include vessel mobilization, vessel section with posterior fossa decompression, autologous material inlay with posterior fossa decompression, and lateral 
vessel retraction assisted with Gore-Tex. It has been reported that surgical decompression leads to significant improvement [1]. In fact, other studies reported surgical intervention did not benefit some patients or temporary improvement with some side effects [5]. Secondly, conservative management is based on addressing every patient complaint individually. Conservative medical management might include aspirin, warfarin sodium, dipyridamole, and analgesics [4].

After reviewing the literature, the table below summarizes the signs, symptoms, and site of indentation of MO, management method, and its efficacy of 4 cases. Although, all mentioned cases in Table 1 are due to VA compression and they presented mainly by a complaint of dizziness, other uncommon symptoms are also present in association with dizziness except one case that was presented only with dizziness.

\section{Case presentation}

\section{Case 1}

A 36-year-old male patient complained of attacks of paroxysmal sense of unsteadies/vertigo in the past 9 months. The attacks were aggravated by turning the head to either side or tilting his head up or down. Attacks lasted for a few minutes. According to the patient, the attacks' intensity were progressive and symptoms improved by rest. It was associated with nausea without vomiting. No history of tinnitus or hearing loss, and no loss of consciousness or falling down. Patients did not have history of any chronic medical diseases.

Office examinations revealed normal cranial nerve function. No spontaneous or gaze-evoked nystagmus, normal head shake test, and normal head thrust test. Videonystagmography (VNG) revealed normal saccade, smooth pursuit, optokinetic nystagmus and bilateral normal and symmetrical caloric responses. The only positive finding which was found in head positional tests (head hanging positions) and Dix-Hallpike test was torsional nystagmus at either side which changes its direction in the right and left sides. The patient did not report a sense of vertigo while present in the provoking position. The nystagmus was not fatigable and not suppressed by fixation. No nystagmus in other head positions.

Magnetic resonance imaging (MRI) was requested for the patient to rule out central lesions. MRI demonstrated an abnormal course of the VA. The VA showed tortuous course of the lateral aspect of $\mathrm{MO}$ and displacing it to the contralateral side (kidney-shaped). There was no evidence of vascular infarction, gray-white differentiation, midline shift or mass effect, or intra- or extra-axial collection. Both seventh and eighth cranial nerves are unremarkable bilaterally (Fig. 1).

\section{Case 2}

Male patient, 59 years old, complained of sense of imbalance precipitated by standing from sitting position and after sneezing. He is diabetic and hypertensive of 10 years duration. General and cranial nerve examination were irrelevant. The audiological assessment revealed bilateral mild to moderate high-frequency sensorineural hearing loss, with excellent speech discrimination. Positional testing revealed left beating nystagmus at all head and body positions not suppressed by fixation. Other VNG tests were within normal. Cranial nerve examination was normal.

MRI head with contrast showed abnormal dilatation, elongation, and tortuosity of V4 segment of VA suggestive of vertebrobasilar dolichoectasia (VBD) compressing

Table 1 Reported cases of vertebral artery compression of the medulla associated with vertigo and/or imbalance

\begin{tabular}{|c|c|c|c|c|c|}
\hline $\begin{array}{l}\text { Patient } \\
\text { age (years) and gender }\end{array}$ & Radiographic findings & Clinical presentation & Treatment & Outcome & Reference \\
\hline $38 / \mathrm{M}$ & $\begin{array}{l}\text { Right VA loop compressing } \\
\text { the cervicomedullary } \\
\text { junction/cranial nerve XI }\end{array}$ & $\begin{array}{l}\text { Torticollis, vertigo, } \\
\text { vomiting, arrhythmias }\end{array}$ & $\begin{array}{l}\text { Microvascular } \\
\text { decompression }\end{array}$ & Cervical stiffness improved & {$[5]$} \\
\hline $68 / M$ & $\begin{array}{l}\text { Medullary compression at } \\
\text { the left lateral surface, base, } \\
\text { and pyramid }\end{array}$ & $\begin{array}{l}\text { Sudden } 20-s \text { imbal- } \\
\text { ance, veering to the } \\
\text { right }\end{array}$ & $\begin{array}{l}\text { Warfarin } \\
\text { sodium }\end{array}$ & No episodes in 1 year & [4] \\
\hline $34 / F$ & $\begin{array}{l}\text { Tortuous left vertebral } \\
\text { compression on the left } \\
\text { side at the base and } \\
\text { tegmenta-basal junction }\end{array}$ & $\begin{array}{l}\text { Multiple episodes of } \\
\text { unsteadiness, aural } \\
\text { fullness, tinnitus, } \\
\text { nausea, headache }\end{array}$ & Aspirin & No further deficits at 1 year & {$[4]$} \\
\hline $32 / F$ & $\begin{array}{l}\text { Tortuous, dilated left } \\
\text { vertebral compression on } \\
\text { the left middle basilar part } \\
\text { and pyramid }\end{array}$ & $\begin{array}{l}\text { Episodes of headache, } \\
\text { vertigo, loss of } \\
\text { consciousness } \\
\text { Torsional nystagmus } \\
\text { to the left, reduced } \\
\text { left corneal reflex }\end{array}$ & $\begin{array}{l}\text { Microvascular } \\
\text { decompression }\end{array}$ & $\begin{array}{l}\text { Episodes disappeared for } 4 \text { months, then } \\
\text { recurred; magnetic resonance imaging } \\
\text { showed displacement of the left } \\
\text { tegmentum and base }\end{array}$ & [4] \\
\hline
\end{tabular}




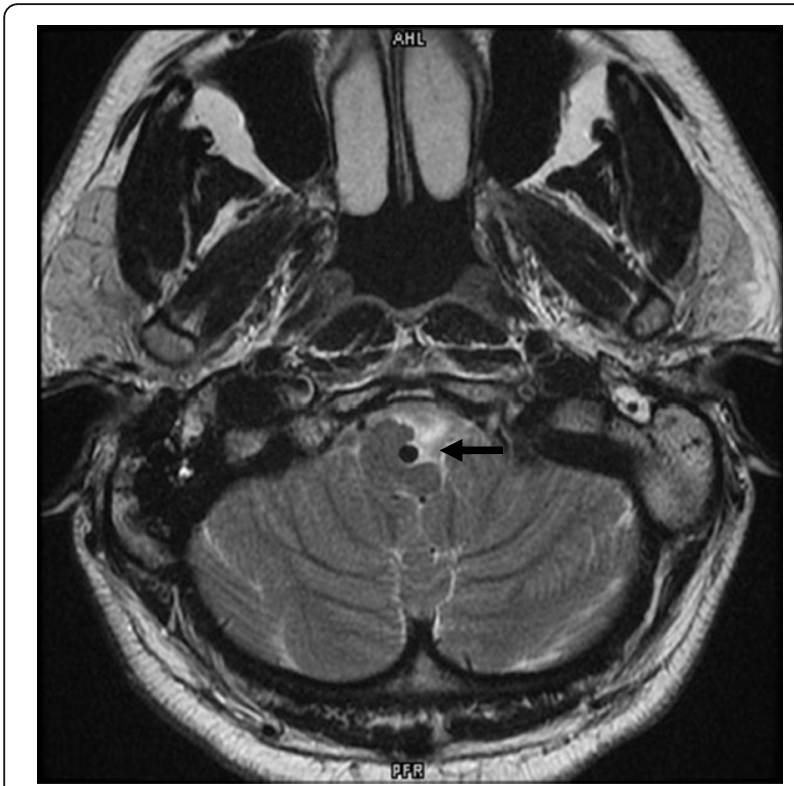

Fig. 1 Brain MRI of case (1) showed the VA compressing the lateral aspect of MO and displacing it to the contralateral side (kidney-shaped) "arrow" the $\mathrm{MO}$ and cisternal component of 8th cranial nerve (Figs. 2 and 3).

\section{Management}

Options for similar conditions usually are either surgical decompression or conservative. The two patients were referred to the neurosurgery clinic for consultation. It was recommended by neurosurgery to start with conservative management and flow the patients closely as there was no any neurological signs. The condition was explained to the patients, and they decided to go with the conservative option. The patient was consulted and instructed to practice central vestibular rehabilitation exercises. Exercises include gaze stabilization exercises, positional exercises, and postural stabilization exercises. After 3 and 6 months of follow-up using dizziness handicap inventory (DHI) Arabic version [6], patients declared a significant improvement with less severe on and off attacks of imbalance. Both patients improved from a moderate degree of handicap to mild degree of handicap as documented by DHI questionnaire.

\section{Discussion}

Dolichoectasia refers to an enlargement and elongation of the vertebrobasilar artery. Asymptomatic cases of

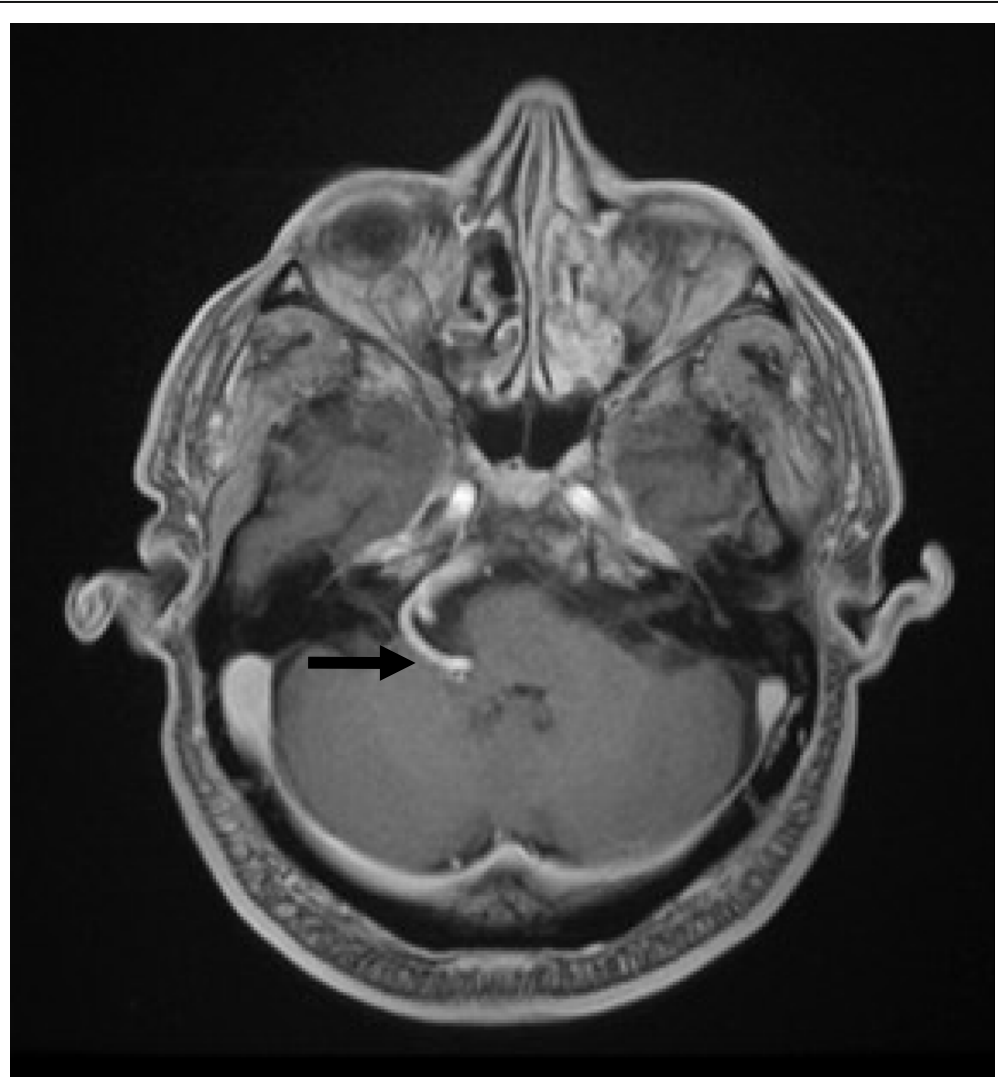

Fig. 2 Brain MRI of case (2) showed VBD compressing the MO (arrow) 


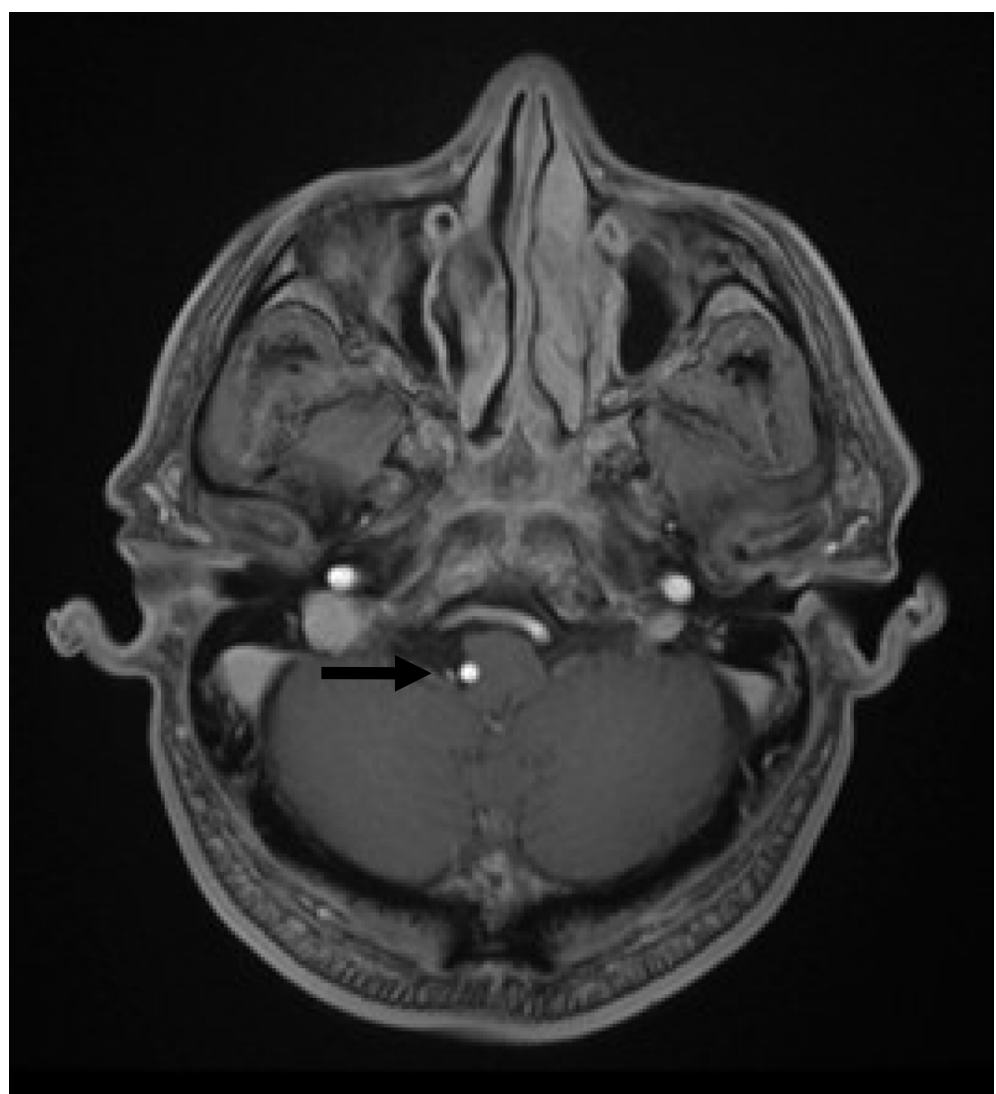

Fig. 3 Brain MRI of case (2) showed VBD compressing the MO (arrow)

dolichoectasia of vertebral and basilar arteries are not uncommon. However, there are reports suggesting that VBD can implicate in neurologic symptoms, both by compression of the brain stem and cranial nerves or by producing transient ischemic attacks [7]. According to the authors' knowledge the isolated symptom of dizziness due to VA compression of the medulla are extremely rare in the literature (Table 1). Astonishingly, there were no neurological abnormalities and cranial nerve affections especially in case (1) in spite of severe compression of the medulla. Due to its gradually progressive nature, the course of brainstem compression by VBD is usually slow. Although sometimes the mass effect of VBD can be very serious, the brainstem can gradually tolerate compression without showing obvious clinical symptoms [8]. In both cases, vertigo and nystagmus are mostly attributed to compression of vestibular nuclei located in the dorsolateral aspect of the medulla; in addition to compression of cisternal component of the 8th cranial nerve in case (2). No MRI evidence of any ischemic effects or brainstem infarction in both cases.

Although, patients had central vestibular disorders that could not allow for central compensation and limit the amount and speed of recovery, research had shown that patients with central vestibular disorders could benefit from vestibular rehabilitation therapy [9]. Accordingly, vestibular rehabilitation exercises were given to our patients and they reported significant functional, physical and emotional benefits with decreased frequency and severity of the dizziness attacks.

\section{Conclusion}

It would be necessary to perform a careful vestibular examination to all vertigo cases. In our patients, the tortious and enlarged VA was demonstrated clearly by the MRI. The sense of vertigo and/or unsteadiness are caused by VA compression of MO. Positional nystagmus with central characteristics can be an isolated sign. Although patients have central vestibular lesions, vestibular rehabilitation exercises can be used as it showed an improvement in our cases.

\section{Abbreviations}

DHI: Dizziness handicap inventory; MO: Medulla oblongata; MRI: Magnetic resonance imaging; VA: Vertebral artery; VBD: Vertebrobasilar dolichoectasia; VNG: Videonystagmography

Acknowledgements Not applicable 


\section{Authors' contributions}

Both MM and IB contributed to the examination and management of study cases. Both MM and IB contributed to writing the manuscript. The authors read and approved the final manuscript.

\section{Funding}

This research did not receive any specific grant from any funding agencies.

\section{Availability of data and materials}

All data are available, including videos.

\section{Ethics approval and consent to participate}

The Otolaryngology Department Board, King Fahad University Hospital, Imam Abdulrahman Bin Faisal University ethically approved the study on 5/1/2018 after thorough presentation by the authors. Consent to participate is not applicable.

\section{Consent for publication}

I am confirming that a copy of written consent is available for the journal. A proof of consent to publish from study participants is ready if it will be requested by the editors and/or reviewers at any time.

\section{Competing interests}

The authors declare that they have no competing interests.

Received: 26 March 2020 Accepted: 20 May 2020

Published online: 04 August 2020

\section{References}

1. Hänggi D, Steiger HJ (2009) Symptomatic vertebral artery conflicts to the medulla oblongata and microsurgical treatment options: review of the literature. Neurosurg Rev 32:143-149

2. Gorton L, Ashour AM, Lebovitz J, Cosola Di A, and Abdulrauf SI (2015) Intractable vomiting caused by vertebral artery compressing the medulla: a case report. J Craniovertebr Junction Spine 6:89-89.

3. Ejma M, Koszewicz M, Podemski R, Marianska K, Budrewicz S, Turek T (2011) Anatomical variation of the vertebral artery clinically mimicking myasthenia gravis. Neurol Sci 32:715-717

4. Savitz SI, Ronthal M, Caplan LR (2006) Vertebral artery compression of the medulla. Arch Neurol 63:234-241

5. Vincentelli F, Caruso G, Rabehanta PB, Rey M (1991) Surgical treatment of a rare congenital anomaly of the vertebral artery: case report and review of the literature. Neurosurgery 28:416-420

6. Alsanosi AA (2012) Adaptation of the dizziness handicap inventory for use in the Arab population. Neurosciences (Riyadh) 17:139-144

7. Ubogu EE, Zaidat OO (2004) Vertebrobasilar dolichoectasia diagnosed by magnetic resonance angiography and risk of stroke and death: a cohort study. J Neurol Neurosurg Psychiatry 75:22-26

8. Yuan YJ, Xu K, Luo Q, Yu JL (2014) Research progress on vertebrobasilar dolichoectasia. Int J Med Sci 11:1039-1048

9. Shepard NT, Telian SA (1995) Programmatic vestibular rehabilitation. Otolaryngol Head Neck Surg 112:173-182

\section{Publisher's Note}

Springer Nature remains neutral with regard to jurisdictional claims in published maps and institutional affiliations.

\section{Submit your manuscript to a SpringerOpen ${ }^{\circ}$ journal and benefit from:}

- Convenient online submission

- Rigorous peer review

- Open access: articles freely available online

- High visibility within the field

- Retaining the copyright to your article 